\title{
Analisis Entri Data Pada Sistem Pengelolaan Gudang Minimarket Berdasarkan Aspek Kualitas Database
}

\author{
Data Entry Analysis Of Minimarket Warehouse \\ Management System Based On Database Quality Aspect \\ Herjuna Ardi Prakosa*1, Nadya Chitayae ${ }^{2}$, Abdul Jalil Rozaqi ${ }^{3}$ \\ 1,2,3 Magister Teknik Informatika, Universitas AMIKOM Yogyakarta \\ E-mail: ${ }^{* 1}$ Herjuna.prakosa@ $@$ students.amikom.ac.id, ${ }^{2}$ nadya.0403@students.amikom.ac.id, \\ 3abdul.13@students.amikom.ac.id
}

\begin{abstract}
Abstrak
Perkembangan teknologi yang semakin maju dan pesat saat ini, banyak kemudahan yang dapat peroleh dalam hal pengolahan data. Proses pengolahan data menggunakan suatu sistem yang terintegrasi dengan baik dapat menghasilkan informasi yang diinginkan secara lebih terstruktur dan rapi. Adanya sistem informasi pengelolaan barang berguna agar dapat mengetahui jumlah stok barang pada gudang dan minimarket, barang yang banyak tertimbun atau berlebih yang tersimpan pada gudang, barang kadaluarsa dan pemesanan barang kepada supplier karena stok persediaan barang yang sudah minim. Pengelolaan data barang pada gudang minimarket ini masih terdapat kelemahan yang mengakibatkan pengimplementasian sistem menjadi kurang efektif, yaitu pada proses entri data yang sama sebanyak 2 (dua) kali sehingga mengakibatkan adanya redundansi data id jenis barang dan mengakibatkan adanya 2 (dua) tabel dengan data yang sama. Solusi yang diberikan yaitu menghilangkan tabel yang dapat mengakibatkan redudansi data. Menghilangkan tabel yang tidak perlu ini sesuai dengan aspek konsistensi (consistency) yang seharusnya tidak memuat redudansi yang tidak perlu, aspek kebenaran (correctness) dan aspek minimalis (minimality).
\end{abstract}

Kata Kunci — aspek kualitas database, database, entri data, sistem pengelolaan gudang

\begin{abstract}
The development of technology that is increasingly advanced and rapid at this time, many conveniences that can be obtained in terms of data processing. Data processing using a well integrated system can produce the desired information in a more structured and neat. The existence of a system of information management of goods is useful in order to know the amount of stock of goods in warehouses and minimarkets, goods that are buried or excess stored in warehouses, expired goods and ordering goods to suppliers because the stock of goods is already minimal. Data management of goods in this minimarket warehouse still has weaknesses which results in the implementation of the system being ineffective, namely in the same data entry process 2 (two) times resulting in redundancy of data id type of goods and resulting in 2 (two) tables with data same. The solution provided is to eliminate tables that can result in data redundancy. Eliminating unnecessary tables is in accordance with aspects of consistency that should not contain unnecessary redundancies, correctness aspects and minimality aspects.
\end{abstract}

Keywords — aspects of database quality, database, data entry, warehouse management systems

\section{Pendahuluan}

Pengelolaan informasi yang dilakukan dengan cepat dan akurat pada masa sekarang ini sangat memungkinkan untuk dilaksanakan. Hal itu disebabkan karena era digital semakin berkembang dan teknologi informasi yang diciptakan juga semakin canggih. Pengelolaan data atau informasi pada suatu organisasi harus ditunjang dengan pemanfaatan teknologi yang baik karena dapat mengurangi atau menghilangkan beberapa tahapan proses kerja sehingga semakin meringankan pekerjaan pengguna. Pengurangan tahapan proses kerja dengan memanfaatkan teknologi infomasi inilah yang merupakan dasar 
penerapan Sistem Informasi Manajemen (SIM). Penggunaan sistem informasi manajemen pada suatu organisasi pemerintah, pendidikan maupun dunia usaha dapat meningkatkan produktivitas, efisiensi serta efektivitas dari organisasi tersebut karena berguna bagi pimpinan dalam melakukan manajemen organisasi.

Fakta-fakta tentang penerapan sistem informasi manajemen yang terjadi di lapangan membuktikan bahwa pengimplementasian sistem informasi yang telah dibuat tidak semuanya berhasil diterapkan. Seperti kasus yang terjadi pada tahun 1990-an yang diteliti oleh Eko Nugroho (1991), pada Daerah Istimewa Yogyakarta (DIY), implementasi sistem informasi manajemen yang telah dibuat hanya berhasil diterapkan rata-rata sekitar $60 \%$. Tingkat keberhasilan ini masih tergolong rendah karena $40 \%$ masih mengalami kegagalan dalam penerapan sistem informasi manajemen. Kegagalan tersebut disebabkan oleh faktor sumber daya manusia yang menggunakan sistem informasi, sehingga penelitian ini menyarankan adanya tindakan lebih lanjut tentang aspek organisasi, manajemen, perilaku, atau teknologi, rekayasa sistem dan database yang dapat mempengaruhi keberhasilan implementasi sistem informasi manajemen pada suatu organisasi [1].

Dino Sumaryono (2012) melakukan penelitian terhadap faktor-faktor yang menyebabkan adanya kegagalan dalam penerapan sistem informasi manajemen pada Dinas Kesehatan Kabupaten Rejang Lebong. Hasil penelitian tersebut membuktikan bahwa penyebab kegagalan penerapan sistem informasi tersebut adalah karena ketidaksesuaian komponen human dan organization, ketidaksesuaian antara komponen human dan technology serta ketidaksesuaian antara komponen organization dengan technology [2].

Sistem informasi diterapkan pada berbagai bidang organisasi. Demikian pula pada bidang penyimpanan barang atau inventory barang pada gudang suatu minimarket. Inventory perlu diterapkan menggunakan teknologi informasi agar dapat mengetahui kepastian persediaan barang yang ada secara terstruktur menggunakan komputer dan database. Agar aktivitas arus lintas barang dapat berjalan dengan lancar maka perlu dilakukan pendataan terhadap semua penerimaan barang yang didapatkan dari supplier, barang yang dipasok ke minimarket, barang yang telah terjual dan penyesuaian (adjustment) terhadap data barang tersebut. Data berperan penting bagi suatu instansi atau organisasi dalam pengambilan keputusan sebagai penunjang sebuah kebijakan [6]. Sistem informasi pengelolaan barang berguna agar dapat mengetahui jumlah stok barang pada gudang dan minimarket, barang yang banyak tertimbun atau berlebih yang tersimpan pada gudang, barang kadaluarsa dan pemesanan barang kepada supplier karena stok persediaan barang yang sudah minim.

Namun kenyataannya pada sistem informasi pengelolaan data barang gudang minimarket ini masih terdapat kelemahan yang mengakibatkan pengimplementasian sistem menjadi kurang efektif, yaitu pada proses entri data yang sama sebanyak 2 (dua) kali sehingga mengakibatkan adanya redundansi data id jenis barang dan mengakibatkan adanya 2 (dua) tabel dengan data yang sama. Penyebab dari kurang maksimalnya proses entri data ini disebabkan karena skema database yang masih kurang sesuai dengan aspek pembangunan database. Sedangkan database merupakan aspek penting dalam pembangunan sistem informasi manajemen. Perancangan basis data adalah proses pembuatan struktur basis data agar dapat menjadi basis data yang baik sehingga dapat menunjang kegiatan operasional dan tujuan perusahaan tersebut. Basis data digunakan untuk menyimpan, merubah dan menampilkan kembali suatu data dengan proses pengolahan data yang mudah dan cepat. [7].

Perancangan desain atau skema suatu basis data sangat mempengaruhi keberhasilan pengimplementasian sistem informasi pada suatu organisasi. Struktur skema basis data yang berkualitas berpengaruh pada kesuksesan penerapan sistem informasi, sehingga semakin berkualitas skema basis datanya, semakin berkualitas pula sistem informasi tersebut. Namun sebaliknya, skema basis data yang kurang berkualitas dapat berpotensi menyebabkan pemasalahan bahkan kegagalan dalam pengimplementasian sistem informasi pada organisasi. [3].

Karena adanya kekurangan pada proses entri data yang mengakibatkan redudansi data, maka perlu dilakukan analisis berdasarkan aspek-aspek kualitas skema database, sehingga dapat dibuktikan bahwa dalam hal entri data ini masih belum sesuai dengan aspek kualitas database. Sehingga berdasarkan analisis tersebut dapat diketahui solusi atau rekomendasi penyelesaian masalahnya. Analisis ini mengacu pada hasil penelitian Olaf Herden (2001) tentang 9 (Sembilan) kriteria kualitas basis data, yaitu aspek kebenaran (correctness), aspek konsistensi (consistency), aspek relevansi (relevance), aspek ruang lingkup (scope), aspek tingkat detail (level of detail), aspek kelengkapan (completeness), aspek minimalis (minimality), aspek kemampuan integrase (ability of integration), serta aspek keterbacaan (readability) [4]. Namun penelitian ini hanya akan melakukan analisis pada 3 aspek yaitu correctness (kebenaran), consistency (konsistensi) dan minimality (minimalis).

Penelitian ini bertujuan untuk mengetahui kualitas skema database dalam hal entri data barang 
pada gudang, sehingga hasil analisis dan penelitian ini diharapkan bisa memberikan masukan dan rekomendasi perbaikan skema basis data sehingga dapat menjadi basis data yang baik dan berkualitas. Usulan rekomendasi perbaikan kualitas basis data dilakukan agar dapat menghindari timbulnya permasalahan pada proses entri data barang di masa mendatang.

\section{Metode Penelitian}

Penelitian ini dilakukan agar dapat mengetahui kualitas skema database dalam hal entri data barang pada gudang sehingga dapat diketahui rekomendasi perbaikan database pada sistem. Untuk mencapai tujuan tersebut penulis melakukan proses analisis dengan tahapan sebagai berikut.

a. Melakukan analisis dan memahami skema database sistem informasi pengelolaan barang pada gudang minimarket. Penulis melakukan pemahaman untuk mengetahui bagaimana skema database yang sedang diterapkan pada sistem informasi pengelolaan barang pada gudang minimarket agar dapat diketahui permasalahan atau ketidaksesuaian pada skema database.

b. Melakukan pengentrian data dalam jumlah yang memadai ke dalam database sistem informasi pengelolaan barang pada gudang minimarket. Pengentrian data ini berguna untuk mengetahui bagaimana proses entri data pada sistem pengelolaan gudang minimarket.

c. Melakukan analisis aspek kebenaran pada proses entri data barang.

Richard Y. Wang dan Diane M. Strong (1996) melakukan penelitian tentang aspek-aspek kualitas yang baik, salah satunya yaitu aspek kebenaran. Aspek kebenaran merupakan aspek yang dapat dibuktikan atau diuji secara teknis pada database yang hendak diuji. Aspek kebenaran akan membuktikan apakah semua komponen telah dimodelkan secara baik dan benar sesuai dengan kebutuhan sistem. Aspek kebenaran digunakan untuk mengukur semua perancangan database sistem, seperti constraint atau Batasan yang dapat melakukan filter data pada tabel sehingga ada jaminan bahwa data yang diinputkan merupakan data yang benar [5].

d. Melakukan analisis aspek konsistensi pada proses entri data barang.

Olaf Herden (2001) melakukan penelitian tentang aspek-aspek kualitas yang baik, salah satunya yaitu aspek konsistensi. Aspek konsistensi merupakan aspek yang dapat dibuktikan atau diuji secara teknis pada database yang hendak diuji. Aspek konsistensi akan membuktikan apakah rancangan dapat diterima dan sesuai dengan keinginan pengguna sistem dengan cara menganalisis konsistensi setiap komponen pada database. Konsistensi data maupun tabel dalam suatu database merupakan suatu keharusan yang harus dilaksanakan demi tercapainya kualitas database yang baik. Pada aspek konsistensi, adanya data yang sama pada suatu tabel atau pada tabel lainnnya merupakan hal yang tidak diperbolehkan karena mengakibatkan pemborosan media penyimpanan pada database [4].

e. Melakukan analisis aspek minimalis pada proses entri data barang.

Menurut penelitian yang dilakukan oleh Olaf Herden (2001), minimalis merupakan aspek yang dapat dibuktikan atau diuji secara teknis pada database yang hendak diuji. Aspek minimalis membuktikan apakah semua tabel telah dimodelkan secara baik dan kompak serta tidak ada perulangan data. Aspek ini juga membuktikan apakah telah mendapatkan kemudahan dalam melakukan pemrograman basis data. Pengujian dilakukan dengan melakukan pengecekan terhadap komponen atau aspek-aspek basis data apakah masih ada yang dimodelkan secara berulang [4].

f. Melakukan analisis aspek-aspek kualitas skema database menggunakan pengujian query Insert dan Select.

g. Mendapatkan kelemahan dan kelebihan sistem berdasarkan proses pengujian query.

h. Mendapatkan rekomendasi-rekomendasi perbaikan pada database sistem informasi pengelolaan barang. 


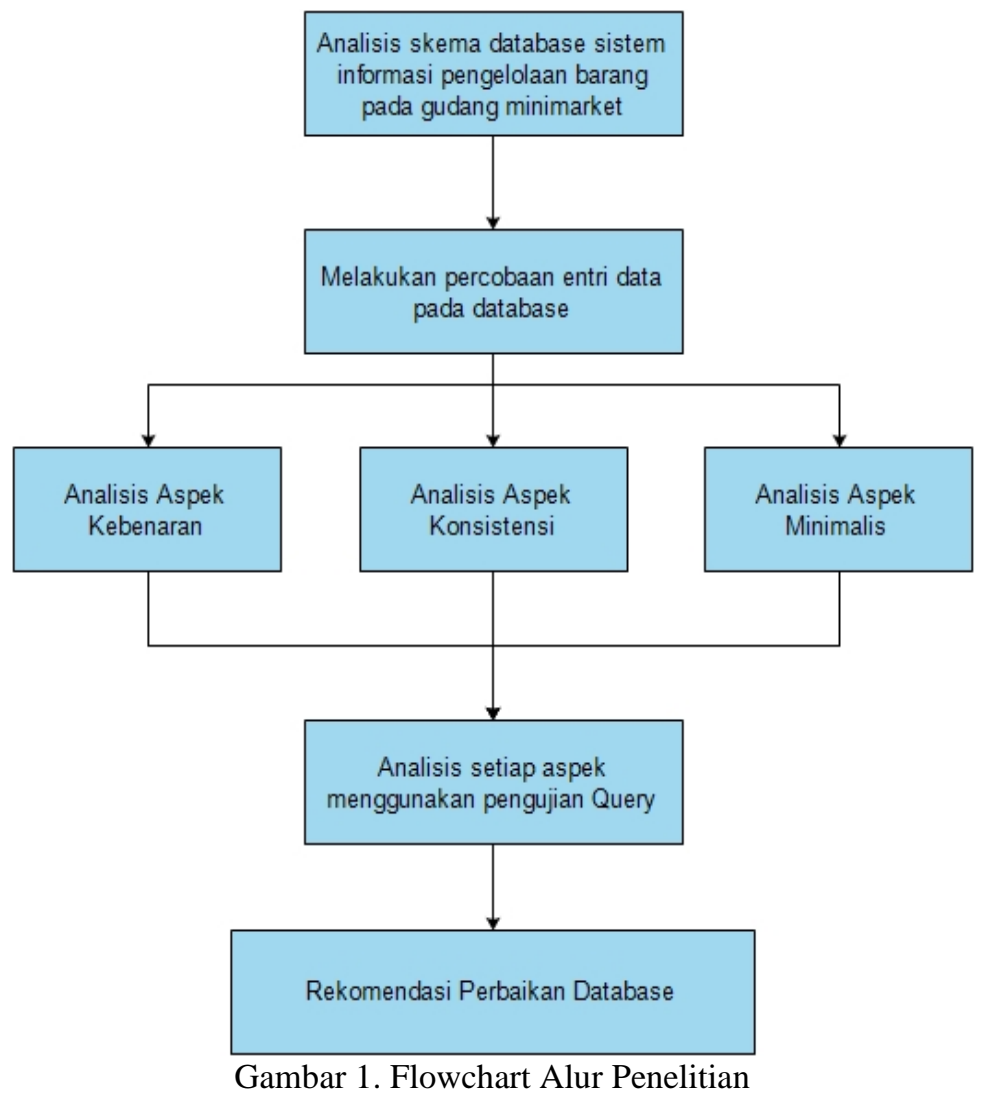

Gambar 1 di merupakan gambar alur penelitian yang dilakukan pada analisis entri data pengelolaan barang pada gudang minimarket. Dimulai dari melakukan percobaan entri data pada database, kemudian dilakukan analisis aspek kebenaran, aspek konsistensi dan aspek minimalis, kemudian dilakukan pengujian query pada setiap aspek untuk mengetahui apakah ada kesalahan dan kejanggalan skema database yang ditemukan pada database sistem informasi pengelolaan barang gudang pada minimarket. Analisis skema database yang dilakukan menggunakan query, akan mendapatkan suatu kesimpulan apakah ditemukan suatu permasalahan pada skema database sehingga dari permasalahan tersebut dapat dibuat suatu rekomendasi perbaikan skema database sehingga database dapat memenuhi kriteria database yang baik dan berkualitas.

\section{Hasil Dan Pembahasan}

Untuk mengoperasikan suatu database digunakan suatu query, yang merupakan perintah untuk dapat menampilkan suatu data dari database dimana dengan menggunakan perintah tersebut akan mengambil data dari tabel pada database. Data pada tabel tersebut dapat ditampilkan secara keseluruhan dan bisa juga ditampilkan sebagian, sesuai dengan yang kita inginkan. Saat melakukan percobaan entri data pada database dalam jumlah data yang memadai, penulis menemukan masalah ketika melakukan entri data pada sistem. Penulis menggunakan query insert untuk memasukkan data pada tabel barang dan tabel stok barang. Saat melakukan insert data barang dan stok barang, ditemukan hal yang tidak sesuai dengan skema basis data yang baik, yaitu proses entri data jenis barang dilakukan sebanyak 2 (dua) kali yaitu pada tabel barang dan tabel stok barang. Proses entri data yang sama mengakibatkan adanya kekeliruan dalam memasukan nama barang, sehingga ada kemungkinan terjadinya salah input data, sehingga hal ini tidak sesuai dengan aspek kebenaran. Kemudian karena adanya proses input sebanyak 2 (dua) kali tersebut mengakibatkan adanya redudansi data jenis barang yang tidak sesuai dengan aspek konsistensi. Dari aspek minimalis, dapat dikatakan database dan sistem masih kurang minimalis karena pengguna masih melakukan input data jenis barang sebanyak 2 (dua) kali, padahal seharusnya input data jenis barang dilakukan sebanyak satu kali saja agak minimalis dari segi struktur database maupun minimalis dalam hal penggunaan sistem oleh admin gudang. 


\section{Minimarket U3 Gontor Home Administrator v Master Data v Proses - Laporan - Minimarket v Acara super admin v}

Dashboard / Barang / Buat Data Barang

Buat Data Barang

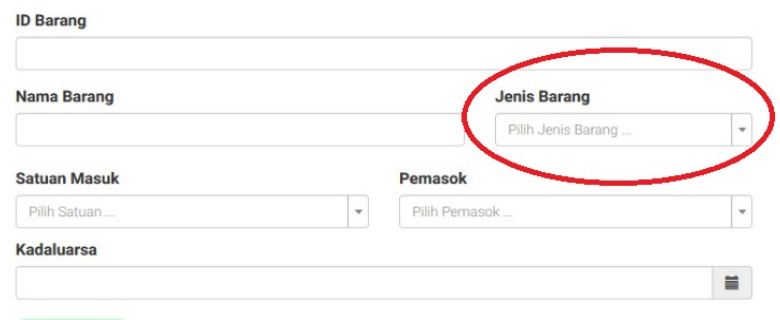

BUAT

Gambar 2. Pengujian Insert Data Barang Gudang

Pada Gambar 2 menjelaskan ketika admin memasukkan data barang yang baru datang dari supplier dan data yang dimasukkan adalah id barang, nama barang, jenis barang, satuan barang, supplier, dan tanggal kadaluarsa. Pada proses ini admin tidak memasukkan jumlah stok barang karena stok barang diinputkan setelah data barang selesai diinputkan.

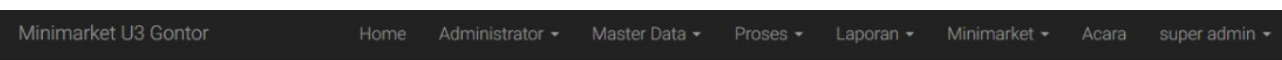

\section{Data Barang Gudang}

\section{BUAT DATA}

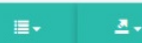

Showing $1-20$ of $\mathbf{3 1}$ items

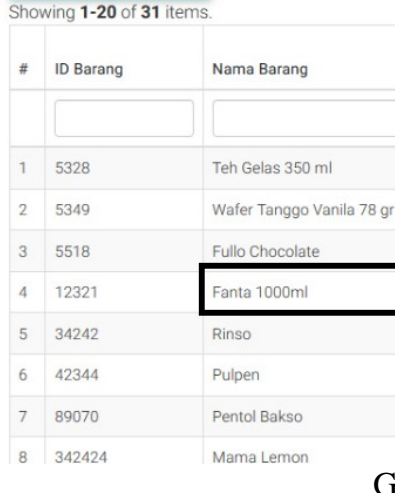

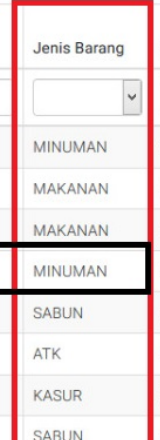

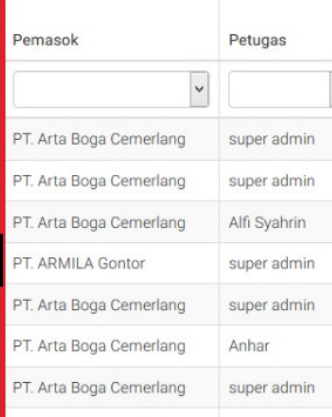

Gambar 3. Hasil Insert Data Barang Gudang

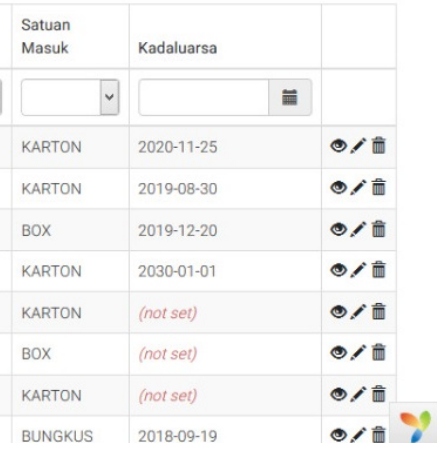

이뇨

Pada Gambar 3 data yang dimasukkan oleh admin sudah masuk kedalam database, pada tahap ini masih belum ada masalah data yang ditampilkan sesuai dengan inputan yang dilakukan admin yaitu id barang, nama barang, jenis barang, satuan barang, supplier, dan tanggal kadaluarsa. 

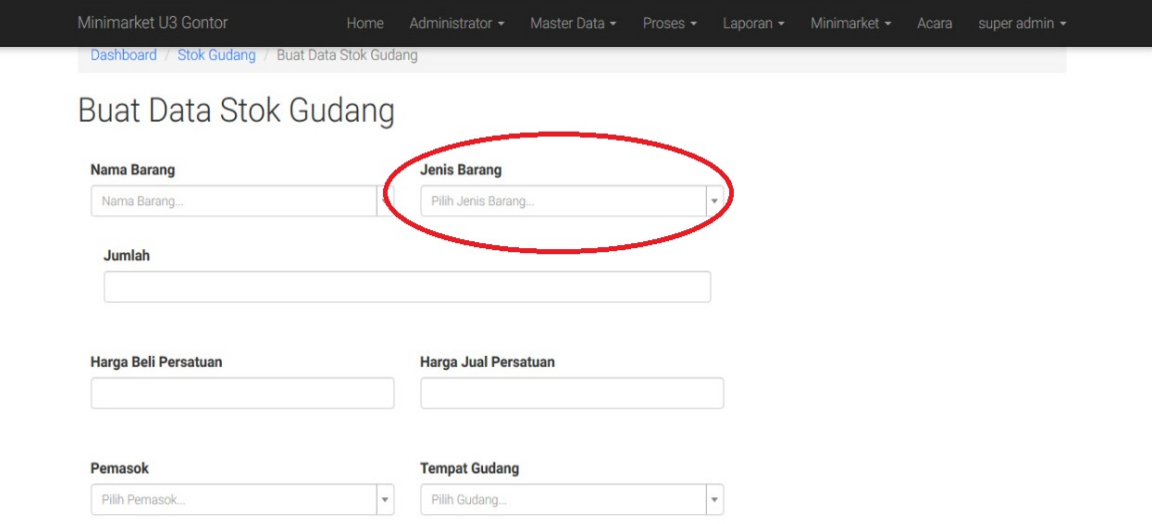

виат

Gambar 4. Pengujian Insert Data Stok Barang pada Gudang

Gambar 4 adalah menjelaskan ketika admin memasukkan data stok barang, admin memasukkan data stok barang dengan cara memilih nama barang kemudian admin memasukkan data stok barang, harga beli, harga jual, supplier dan tempat gudang. Jika dianalisis dari aspek kebenarannya dapat dimungkinkan admin salah memilih nama barang ketika admin memasukkan data stok barang. Contoh kasus ada barang masuk dari supplier yaitu Aqua $330 \mathrm{ml}$ sebanyak 10 buah dan Aqua $450 \mathrm{ml}$ sebanyak 50 buah, pada pengentrian pertama admin memasukkan kedua barang ini, pada pengentrian kedua admin memasukkan data stok barang, yang menjadi masalah adalah dimungkinkannya admin memilih nama barang Aqua $450 \mathrm{ml}$ dan memasukkan stok barang 10 buah padahal stok untuk Aqua $450 \mathrm{ml}$ adalah 50 buah.

Masalah yang selanjutnya adalah admin memasukkan data jenis barang dan supplier yang kedua kalinya pada tabel stok barang yang tidak perlu karena jenis barang dan supplier yang sudah ada pada tabel barang.

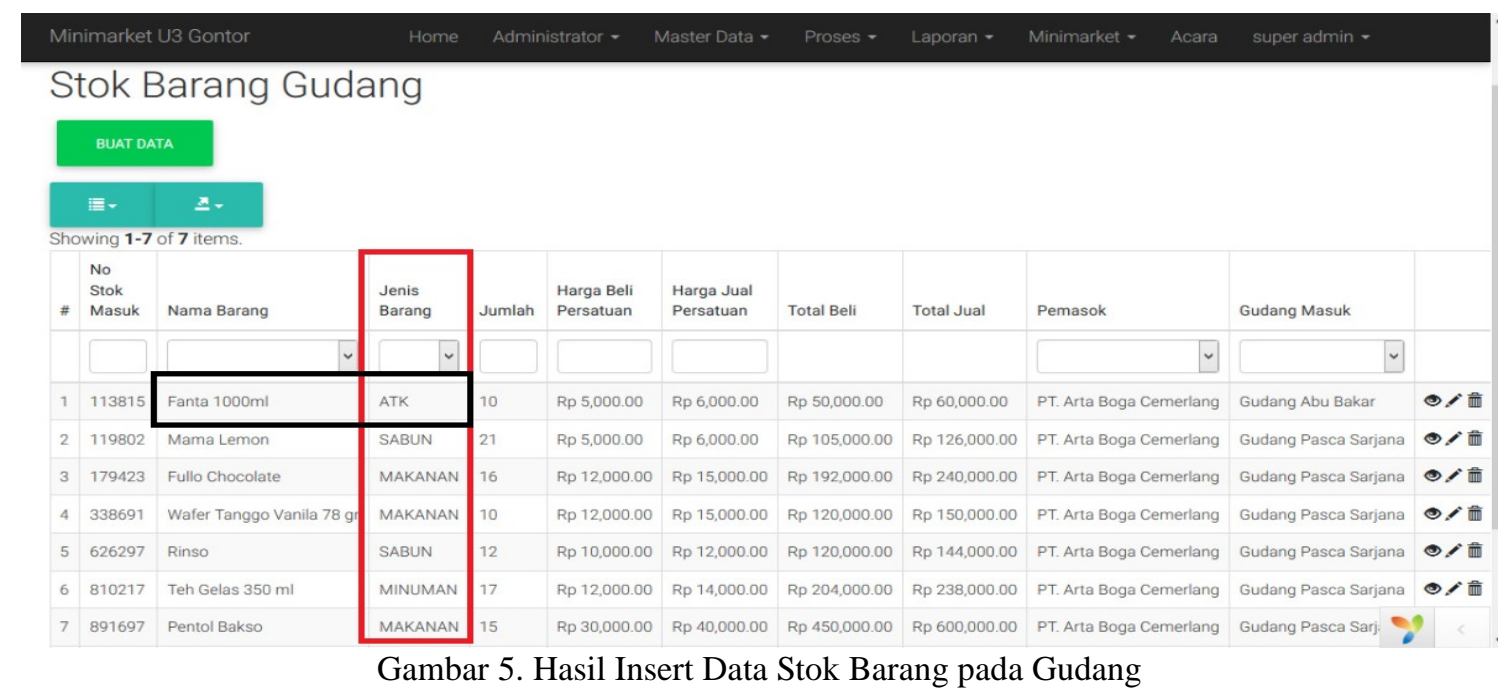

Pada Gambar 5 menjelaskan hasil insert data stok barang, dikarenakan ketika memasukkan stok barang admin harus memasukkan jenis barang lagi, disini penulis menguji dengan memasukkan jenis barang "ATK" pada barang "Fanta 1000ml" yang seharusnya jenis barang dari Fanta 1000ml adalah Minuman. Hasil dari insert jenis barang yang berbeda ternyata berhasil, jadi Fanta 1000ml memiliki jenis barang "ATK" pada tabel stok, dan ini mengakibatkan satu barang memiliki dua jenis barang yang berbeda. 


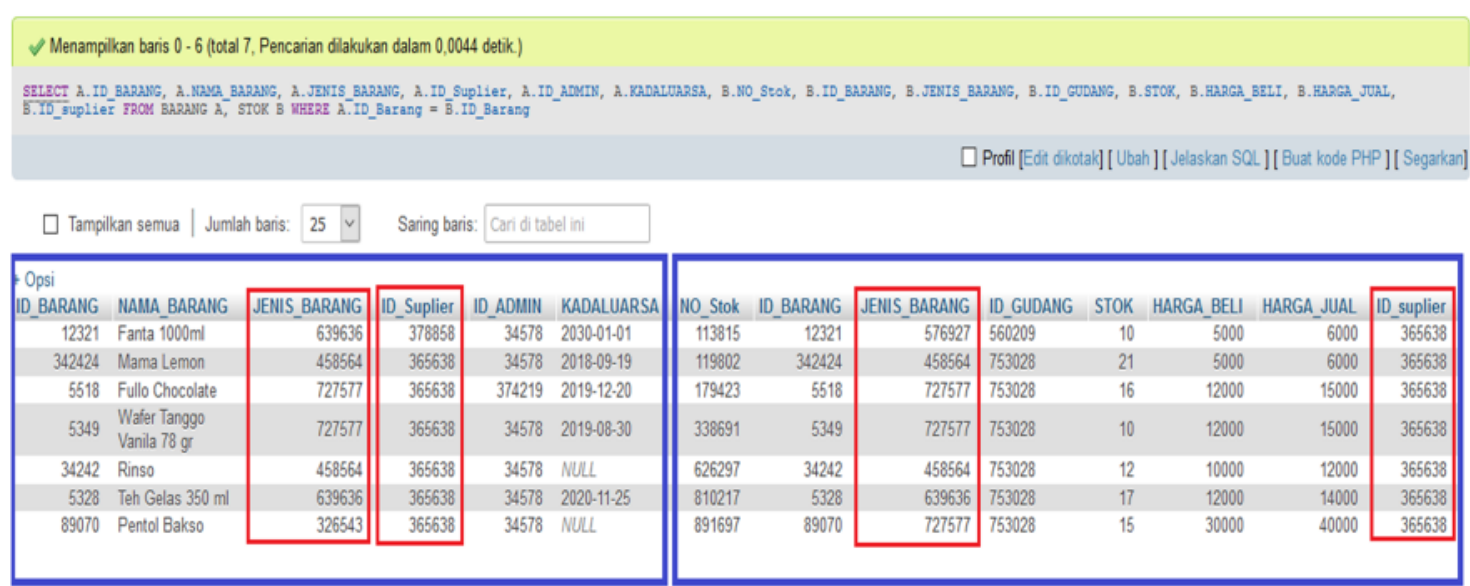

Gambar 6. Redundansi Data Barang

Gambar 6 menjelaskan ketika peneliti melakukan query select untuk tabel barang dan tabel stok, kedua tabel ini berelasi dengan menggunakan atribut id barang tetapi kedua tabel ini memiliki atribut yang sama selain id barang yaitu jenis barang dan id supplier. Sebelumnya peneliti menguji dengan memasukkan data jenis barang yang berbeda ketika memasukkan data stok barang dan berhasil, kemudian peneliti melakukan pengujian lagi dengan melakukan query update data jenis barang dan id supplier pada tabel stok dan berhasil, sehingga field jenis barang dan id supplier pada tabel stok berbeda dengan yang ada pada tabel barang padahal memiliki id barang yang sama. Redudansi yang terjadi adalah satu barang bisa memiliki dua jenis barang dan id supplier yang berbeda.

Berdasarkan analisis yang dilakukan, terdapat rekomendasi perbaikan database agar memenuhi aspek kualitas database yang baik. Rekomendasi perbaikan struktur database yang perlu dilakukan adalah pengerucutan atau menghilangkan tabel yang dapat mengakibatkan redudansi data. Menghilangkan tabel yang tidak perlu ini sesuai dengan aspek konsistensi (consistency) yang seharusnya tidak memuat redudansi yang tidak perlu, baik dalam tabel yang sama maupun tabel yang berbeda. Redudansi data adalah duplikasi data pada beberapa tempat atau tabel atau file data, dimana data yang tersimpan pada penyimpanan tersebut merupakan data yang sama sehingga terjadi pemborosan storage atau tempat penyimpanan. Data yang disimpan pada lebih dari satu lokasi ini dapat mengakibatkan habisnya tempat penyimpanan data serta dapat menyebabkan inkonsistensi data. Menurut Olaf Herden (2001), aspek konsistensi merupakan aspek yang dapat dibuktikan atau diuji secara teknis pada database yang hendak diuji. Aspek konsistensi akan membuktikan apakah rancangan dapat diterima dan sesuai dengan keinginan pengguna sistem dengan cara menganalisis konsistensi setiap komponen pada database. Konsistensi data maupun tabel dalam suatu database merupakan suatu keharusan yang harus dilaksanakan demi tercapainya kualitas database yang baik. Pada aspek konsistensi, adanya data yang sama pada suatu tabel atau pada tabel lainnnya (redudansi data) merupakan hal yang tidak diperbolehkan karena mengakibatkan pemborosan media penyimpanan pada database [4]. Tabel pada database sistem informasi pengelolaan barang gudang yang dihilangkan yaitu tabel stok barang, yang akan disatukan dengan tabel barang gudang, hal ini bertujuan untuk menghindari redudansi data yang tidak sesuai dengan aspek konsistensi. 


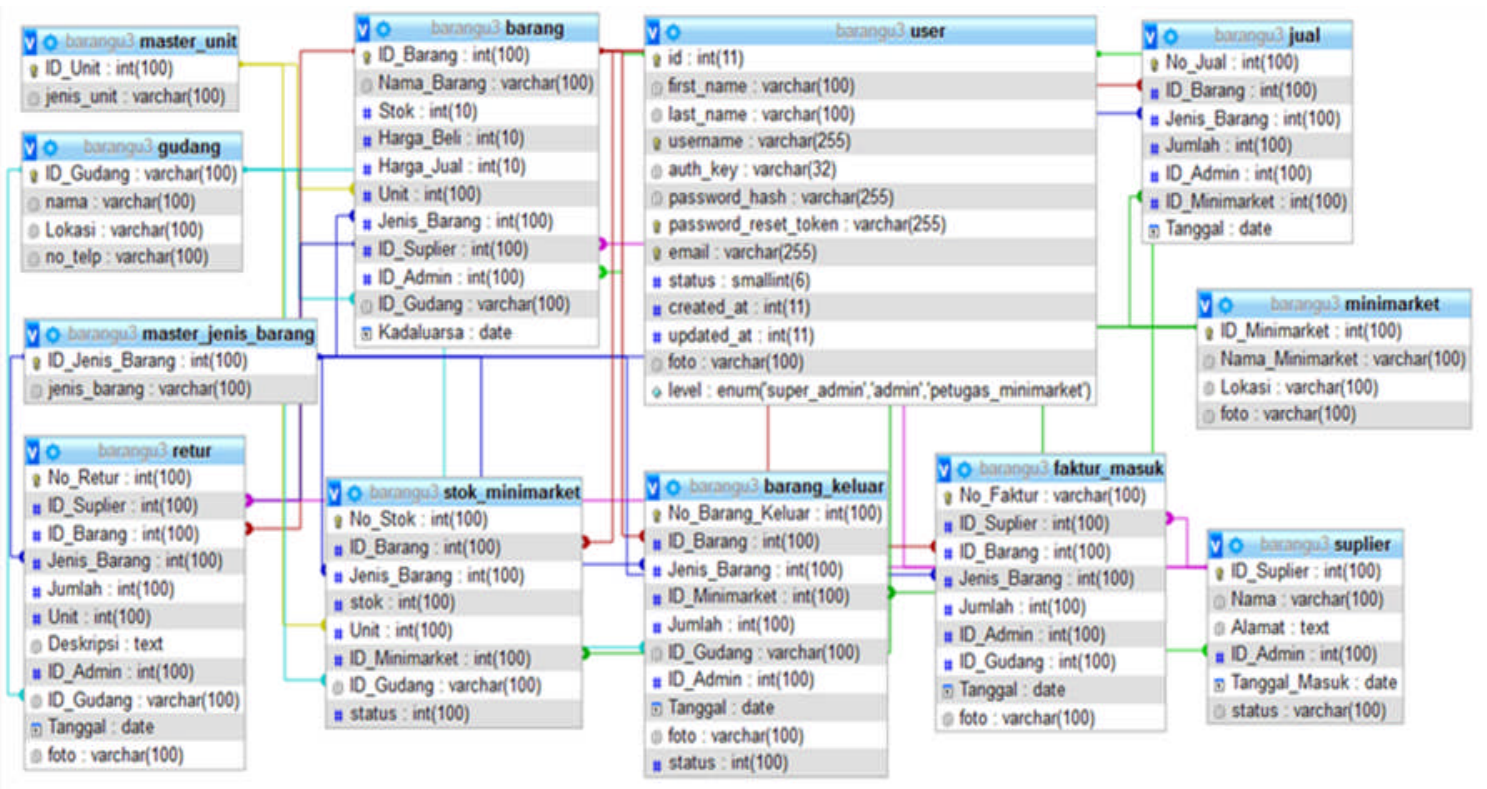

Gambar 7. Rekomendasi Rancangan Database

Gambar 7 merupakan rekomendasi rancangan skema database agar tidak terjadi redudansi data karena tabel stok sudah dihilangkan dan dijadikan satu dengan tabel barang.

Pada rancangan database sebelumnya terdapat 2 (dua) tabel yang memuat data yang sama yaitu tabel stok dan tabel barang. Keadaan tersebut menyebabkan redudansi data, sehingga pada rekomendasi pertama, tabel stok dihilangkan dan dijadikan satu dengan tabel barang. Penggabungan tabel menjadi satu ini juga mempengaruhi entri data. Sebelumnya karena terdapat 2 (dua) tabel untuk melakukan entri data, maka sistem memiliki 2 (dua) form penginputan data yaitu form input data barang dan input data stok barang. Karena sekarang tabel pada database telah dijadikan satu yaitu pada tabel barang, maka proses entri data barang tersebut juga dijadikan 1 form entry data saja. Hal ini berhubungan dengan aspek kualitas database tentang minimalisnya suatu database yang memudahkan pengguna dalam mengoperasikan sistem informasi pengelolaan barang gudang minimarket karena hanya melakukan entri data barang sebanyak 1 (satu) kali saja. Seperti penelitian yang dilakukan oleh Olaf Herden (2001), minimalis merupakan aspek yang dapat dibuktikan atau diuji secara teknis pada database yang hendak diuji. Aspek minimalis membuktikan apakah semua tabel telah dimodelkan secara baik dan kompak serta tidak ada perulangan data. Aspek ini juga membuktikan apakah telah mendapatkan kemudahan dalam melakukan pemrograman basis data. Pengujian dilakukan dengan melakukan pengecekan terhadap komponen atau aspek-aspek basis data apakah masih ada komponen yang dimodelkan secara berulang [4]. Pada Gambar 8 merupakan proses entri data barang sebanyak 1 (satu) kali saja sehingga sesuai dengan aspek minimalis dan konsistensi.

\begin{tabular}{|rlrrrrrrrr|r|}
\hline ID_Barang & Nama_Barang & Stok & Harga_Beli & Harga_Jual & Unit & Jenis_Barang & ID_Suplier & ID_Admin & ID_Gudang & Kadaluarsa \\
\hline 1112 & Keju Lapis & 20 & 3000 & 5000 & 162926 & 727577 & 365638 & 34578 & 753028 & $2031-01-11$ \\
5328 & Teh Gelas $350 \mathrm{ml}$ & 17 & 900 & 1000 & 162926 & 639636 & 365638 & 34578 & 753028 & $2020-11-25$ \\
\hline 5349 & Wafer Tanggo Vanila 145 gr & 50 & 7400 & 1500 & 162926 & 727577 & 365638 & 34578 & 753028 & $2019-08-30$ \\
5518 & Fullo Chocolate & 100 & 450 & 500 & 251014 & 727577 & 365638 & 374219 & 753028 & $2019-12-20$ \\
\hline 34242 & Rinso $800 \mathrm{gr}$ & 35 & 16900 & 20000 & 162926 & 458564 & 365638 & 34578 & 753028 & NULL \\
\hline 42344 & Pulpen & 45 & 1000 & 2000 & 251014 & 576927 & 365638 & 451233 & 753028 & NULL \\
\hline 89070 & Pentol Bakso & 80 & 950 & 1500 & 162926 & 326543 & 365638 & 34578 & 753028 & $2020-01-31$ \\
\hline 342424 & Mama Lemon & 23 & 1300 & 2000 & 855461 & 458564 & 365638 & 34578 & 753028 \\
\hline
\end{tabular}

Gambar 8. Proses Entri Data Barang Pada 1 (Satu) Form Entri Data 
Proses pembuatan form entri data menjadi satu ini juga memberikan kemudahan bagi programmer karena hanya menggunakan query insert satu kali saja untuk melakukan pengentrian data barang. Query yang digunakan untuk melakukan insert data barang yang digunakan yaitu sebagai berikut.

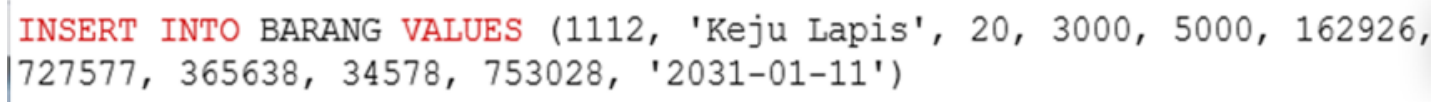

\begin{tabular}{|rlrrrr|r|rrr|r|r|}
\hline ID_Barang & Nama_Barang & Stok & Harga_Beli & Harga_Jual & Unit & Jenis_Barang & ID_Suplier & ID_Admin & ID_Gudang & Kadaluarsa \\
\hline 1112 & Keju Lapis & 20 & 3000 & 5000 & 162926 & 727577 & 365638 & 34578 & 753028 & $2031-01-11$ \\
\hline 5328 & Teh Gelas $350 \mathrm{ml}$ & 17 & 900 & 1000 & 162926 & 639636 & 365638 & 34578 & 753028 & $2020-11-25$ \\
\hline 5349 & Wafer Tanggo Vanila 145 gr & 50 & 7400 & 1500 & 162926 & 727577 & 365638 & 34578 & 753028 & $2019-08-30$ \\
\hline 5518 & Fullo Chocolate & 100 & 450 & 500 & 251014 & 727577 & 365638 & 374219 & 753028 & $2019-12-20$ \\
\hline 34242 & Rinso $800 \mathrm{gr}$ & 35 & 16900 & 20000 & 162926 & 458564 & 365638 & 34578 & 753028 & NULL \\
\hline 42344 & Pulpen & 45 & 1000 & 2000 & 251014 & 576927 & 365638 & 451233 & 753028 & NULLL \\
\hline 89070 & Pentol Bakso & 80 & 950 & 1500 & 162926 & 326543 & 365638 & 34578 & 753028 & $2020-01-31$ \\
\hline 342424 & Mama Lemon & 23 & 1300 & 2000 & 855461 & 458564 & 365638 & 34578 & 753028 & NULL \\
\hline
\end{tabular}

Gambar 9. Tidak Ada Redudansi Data Pada Proses Entri Data Barang

Gambar 9 menampilkan tabel barang dengan query select, tabel ini merupakan gabungan dari tabel barang dan stok, sehingga proses entri data hanya satu kali saja dan sudah tidak ada lagi redudansi data jenis barang dan supplier.

Selain terdapat kekurangan pada sistem database, sistem ini juga memiliki kelebihan yang terletak pada aspek relevansi. Menurut Olaf Herden (2001), aspek relevansi merupakan aspek yang dapat dibuktikan atau diuji secara teknis pada database yang hendak diuji. Aspek relevansi ini digunakan untuk mengetahui apakah hubungan antar tabel sudah memiliki relasi yang sesuai atau tidak. Aspek ini menguji skema basis data yang relevan, baik pada setiap tabel maupun relasi antar tabel [4]. Pada sistem informasi pengelolaan barang gudang minimarket ini semua tabel telah terkoneksi dengan tabel yang berelasi sehingga hal ini membuktikan bahwa skema databasenya sudah sesuai dengan aspek relevansi.

\section{Kesimpulan}

Penelitian ini berhasil melakukan analisis entri data pada sistem pengelolaan gudang minimarket berdasarkan aspek kualitas basis data yaitu aspek kebenaran, aspek konsistensi dan aspek minimalis. Proses entri data barang sebanyak 2 (dua) kali data yang sama mengakibatkan adanya kekeliruan dalam memasukan nama barang, sehingga ada kemungkinan salah input, hal ini tidak sesuai dengan aspek kebenaran. Kemudian karena adanya proses input sebanyak 2 (dua) kali tersebut mengakibatkan adanya redudansi data jenis barang yang tidak sesuai dengan aspek konsistensi dan aspek minimalis. Maka berdasarkan hasil analisis tersebut penulis merekomendasikan penyelesaian agar masalah yang ditemukan tersebut tidak menimbulkan masalah dikemudian hari dalam hal entri data. Penulis merekomendasikan penggabungan tabel stok pada tabel barang. Tabel stok dihilangkan dan dijadikan satu dengan tabel barang. Rekomendasi selanjutnya adalah melakukan proses entri data pada 1 (satu form) saja sehingga pengguna tidak melakukan input data barang secara berulang.

Pada database ini selain terdapat kekurangan pada sistem, pada skema database nya juga memiliki kelebihan yang terletak pada aspek relevansi. Relevansi merupakan aspek yang dapat dibuktikan atau diuji secara teknis pada database yang hendak diuji. Aspek relevansi ini digunakan untuk mengetahui apakah hubungan antar tabel sudah memiliki relasi yang sesuai atau tidak. Pada sistem informasi pengelolaan barang gudang minimarket ini relasi tabel telah sesuai dan terkoneksi dengan tabel yang berelasi, sehingga hal ini membuktikan bahwa skema databasenya sudah sesuai dengan aspek relevansi. 


\section{Saran}

Adapun saran untuk pengembangan penelitian selanjutnya yaitu diharapkan dapat mengimplementasikan hasil rekomendasi perbaikan basis data ke tahap selanjutnya seperti tahap pemrograman dan desain tampilan sistem yang mendukung perbaikan basis data tersebut. Sehingga sistem memiliki kualitas dan memenuhi aspek basis data yang baik. Jika basis data dapat terpenuhi, maka program juga dapat dijalankan dengan baik. Selanjutnya akan lebih baik lagi jika analisis terhadap aspek kualitas basis data dapat dilakukan pada 6 aspek lainnya yaitu aspek relevansi (relevance), aspek ruang lingkup (scope), apek tingkat detail (level of detail), aspek kelengkapan (completeness), aspek kemampuan integritas (ability of integration) serta aspek keterbacaan (readability) agar kualitas basis data menjadi semakin baik lagi.

\section{DAFTAR PUSTAKA}

[1] Eko Nugroho, 1991, Pengaruh Struktur Organisasi dan Sumber Daya Manusia Terhadap Keberhasilan Implementasi Sistem Informasi Manajemen dalam Organisasi, Tesis Program Magister Sains, Prodi Akuntansi, Fakultas Ekonomi, UGM, Yogyakarta.

[2] Dino Sumaryono, 2012, Analisis Faktor-Faktor Penyebab Kegagalan Penerapan Sistem Informasi Manajemen Kepegawaian (SIMPEG) di Dinas Kesehatan Kabupaten Rejang Lebong, Tesis, Program Magister Kesehatan Masyarakat, UGM, Yogyakarta.

[3] Suwanto Raharjo, Edhy Sutanta, Ema Utami, 2007, Analisis Aspek-Aspek Kualitas Schema Database, Seminar Nasional Teknologi, Yogyakarta.

[4] Olaf Herden, 2001, Measuring Quality of Database Schemas by Reviewing-Concept, Criteria and Tool, Oldenburg Research and Development Institute for Computer Science Tools and Systems (OFFIS), Escherweg 2, 26121 Oldenburg, Germany.

[5] Richard Y. Wang dan Diane M. Strong, 1996, Beyond Accuracy: What Data Quality Means to Data Consumers, Journal of Management of Information Systems, Vol 12, pp 5-33.

[6] Ria Andriani, Ade Pujianto, Selvy Megira, Annisa Rahayu Pangeti, Dalilah Razan Samhana, Dwi Rahayu, Imam Ainudin Pirmansyah, Ema Utami, 2017, Perancangan Basis Data Pada Website E-Kartu Nikah, Jurnal VOI Voice of Informatics Vol 6, No 2.

[7] Gat, 2015, Perancangan Basis Data Perpustakaan Sekolah dengan Menerapkan Model Data Relasional. Citec Journal, Vol 2, No 4. 